\title{
In vitro evaluation of the tension band suture method for proximal humerus fracture treatment
}

Hideaki Ishii ${ }^{1,2}$, Takanori Shintaku', Shu Yoshizawa' ${ }^{1}$ Misato Sakamoto ${ }^{1}$, Takao Kaneko ${ }^{1}$, Yoshiro Musha ${ }^{1}$ and Hiroyasu Ikegami ${ }^{*}$

\begin{abstract}
Background: Proximal humeral fractures are common, and more than half occur in patients over 65 years of age. Operative treatment may be recommended for displaced, complicated fractures; however, surgery may lead to displacement of the greater tuberosity or humeral head. Supplemental tension band sutures have been recommended to prevent such a complication. In this study, we investigate the best combination of suture, washer, and threading angle for proximal humeral fractures from a mechanical view.

Methods: The mechanical durability of 18 combinations of suture materials (Fiberwire, Ethibond, and Surgilon), threading washers (ring washer, disc washer), and threading angles (15 or $45^{\circ}$ ) were examined via a cyclic loading test.

Results: The most durable combination in the cyclic loading test consisted of threading the Fiber Wire to the washer ring using only one hole (ring washer-1) at $45^{\circ}$. In contrast, the most vulnerable combination was threading Ethibond to the washer disc at $15^{\circ}$. Breakage of all suture materials occurred at the suture-washer interface, and no failure or loosening of the knots was observed. FiberWire gradually eroded until the loss of equilibrium; whereas the rupture of Ethibond and Surgilon occurred suddenly.

Conclusions: From a mechanical viewpoint, we demonstrated that applying a supplemental tension band suture using FiberWire with a single-hole ring washer threaded at a wider angle is recommended.
\end{abstract}

Keywords: Tension band suture, Washer, Proximal humeral fractures, FiberWire, Ethibond, Surgilon, Targon PH-P, Intramedullary nail

\section{Background}

Proximal humeral fractures account for $5.7 \%$ of all fractures, and incidence increases with age [1]. They are the third most frequent fracture in the elderly, after fractures of the hip and distal radius fractures, and more than half occur in patients over 65 years of age. Low bone mineral density and a high fall risk score are known risk factors

\footnotetext{
* Correspondence: hiroyasu.ikegami@med.toho-u.ac.jp 'Department of Orthopaedic Surgery (Ohashi), School of Medicine, Toho University, 2-22-36 Ohashi, Meguro-ku, Tokyo 153-8515, Japan Full list of author information is available at the end of the article
}

$[2,3]$. Non-operative treatment is reasonable for most stable, minimally displaced proximal humeral fractures [4]. However, approximately $20 \%$ of displaced, complicated fractures may benefit from operative treatment [5]. Many surgical techniques have been described to prevent complications, such as humeral malunions, nonunions, stiffness, and post-traumatic arthrosis, which can be significantly disabling [6]. Open reduction and internal fixation (ORIF), using either angular or sliding stable antegrade locking intramedullary nails (IMN) or anatomically designed proximal humeral angular stable

(c) The Author(s). 2020 Open Access This article is licensed under a Creative Commons Attribution 4.0 International License, which permits use, sharing, adaptation, distribution and reproduction in any medium or format, as long as you give appropriate credit to the original author(s) and the source, provide a link to the Creative Commons licence, and indicate if changes were made. The images or other third party material in this article are included in the article's Creative Commons licence, unless indicated otherwise in a credit line to the material. If material is not included in the article's Creative Commons licence and your intended use is not permitted by statutory regulation or exceeds the permitted use, you will need to obtain permission directly from the copyright holder. To view a copy of this licence, visit http://creativecommons.org/licenses/by/4.0/ The Creative Commons Public Domain Dedication waiver (http://creativecommons.org/publicdomain/zero/1.0/) applies to the data made available in this article, unless otherwise stated in a credit line to the data. 
plates, is one standard surgical treatment option for proximal humeral fractures [7]. These modern implants offer high primary stability, which can allow early functional exercises and provide good to excellent results in the majority of patients, with an acceptable complication rate $[8,9]$. However, considerable issues exist after surgery, especially for the elderly due to their poor bone quality, and no single approach is considered to be the standard of care [5]. Displacement of the greater tuberosity and humeral head are common complications of surgery and can lead to malunion or nonunion [7, 10, 11]. Several studies have recommended tension band sutures for the prevention of this complication [12-17]. However, to the best of our knowledge, no study has focused on the variety and combination of components, such as the washer, suture material, and threading angle, of tension band sutures in detail. The purpose of this study is to explore the most suitable method of tension band suture to treat proximal humeral fractures using IMN.

\section{Methods}

\section{Experimental device}

The testing device consisted of a fixed washer, the suture material, and a weight. Non-absorbable sutures were passed through the washers, tightened with screws vertically to the long axis, and connected to a weight (Fig. 1). The weight was set to $5 \mathrm{kgf}$, in accordance with an advanced trial. A cyclic loading test was performed with reciprocating motion at $0.2 \mathrm{~Hz}$ using a Servo pulsar (EHF-LV005k1-A10; Shimadzu Corp., Kyoto, Japan) in $10 \mathrm{~mm}$ strokes. The load ranged from approximately 15 $\mathrm{N}$ to $90 \mathrm{~N}$, changing every second in conjunction with the motion of the piston. The maximal load of $90 \mathrm{~N}$ was considered to be well within the physiologic range, representing only $30 \%$ of the load that could be delivered

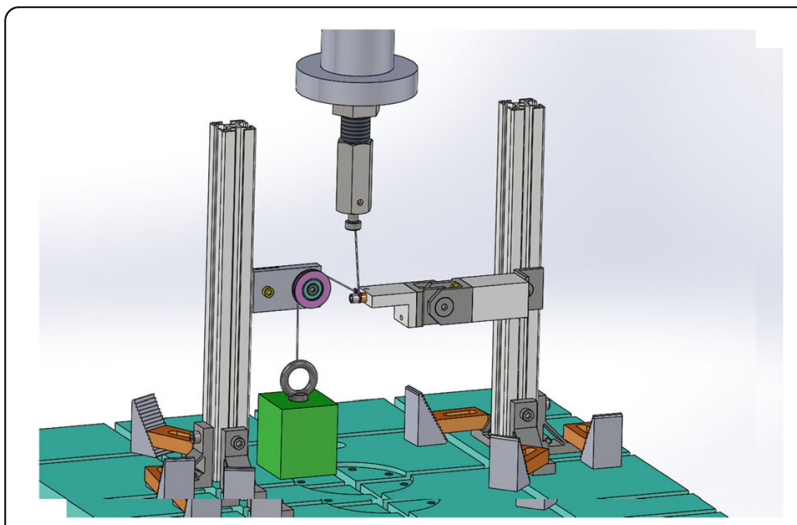

Fig. 1 Schema of Servo pulsar used for loading test. Suture materials were passed through the washer which was tightened with screws. The edge of thread was tied to rodand weight rigidly by use of 5 square knots by the maximal contraction of muscles [18]. The loading cycle was continued until failure of the suture material (Fig. 2) and observation of the weight touching the ground. The number of vertical motions was counted. The mechanical durability of 18 combinations of suture materials $(n=3)$, threading washers $(n=3)$, and threading angles $(n=2)$ were compared. Each combination was tested in the same condition three times.

\section{Suture materials}

Three different non-absorbable suture materials commonly used in orthopedic surgery were compared: FiberWire (Arthrex, Inc., FL, USA); Ethibond (ETHICON, Inc., NJ, USA); and Surgilon (Medtronic, Inc., MN, USA). All sutures used were of standard size (no. 2) and kept moist throughout testing with $0.9 \%$ of saline solution to mimic the internal environment. One end of each suture was tied to the rod, and the other side was tied to the weight after threading the washer with five square knots.

\section{Washers and threading methods}

Two different TARGON PH-P (AESCULAP, Inc., PA, USA) washers (ring washer, disc washer) were utilized (Fig. 3). The ring washer is pure titanium and has two circular suture holes at the top, adjoining on the same side. The disc washer is made of a titanium alloy,

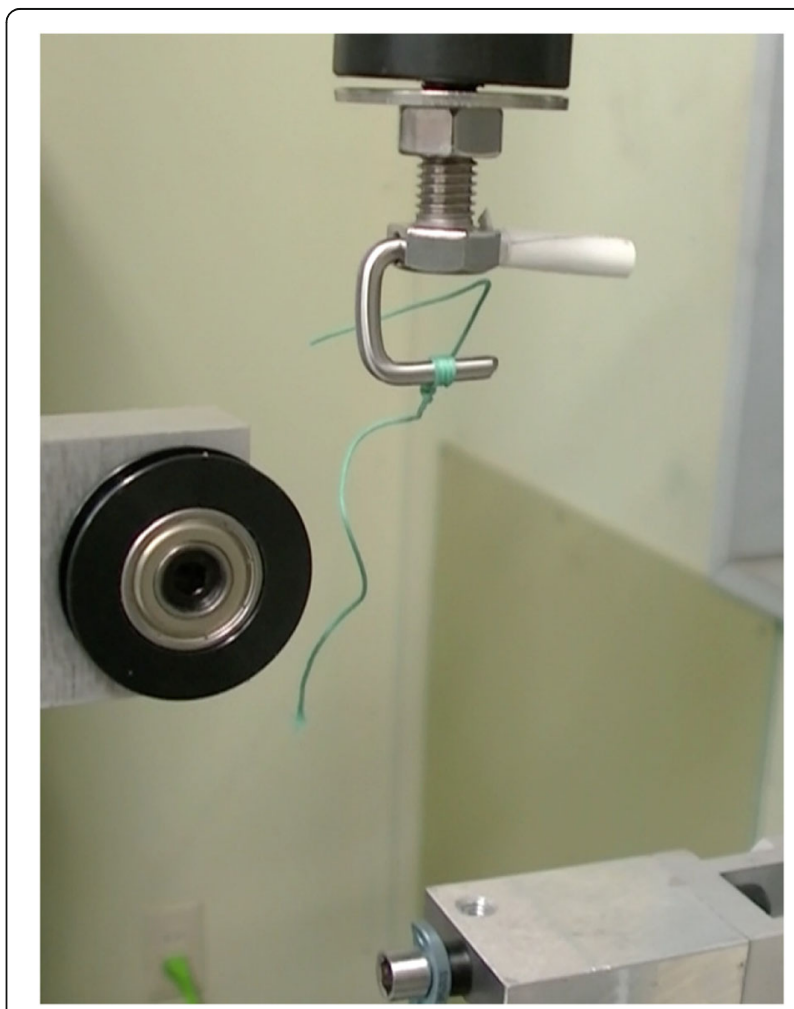

Fig. 2 A broken suture 


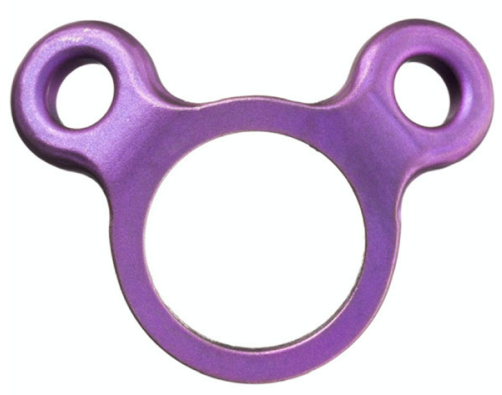

(A)
(B)

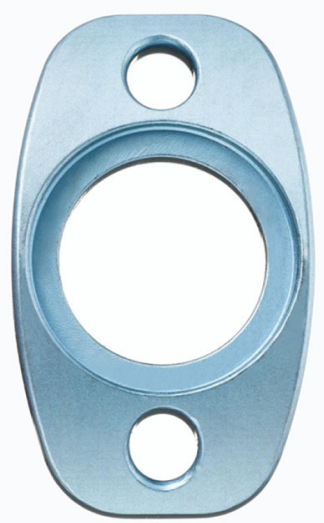

Fig. 3 Two washers used for tension band suture in this study. Ring washer (a) and disc washer (b) are attached to Targon PH-P

consisting of $90 \%$ titanium, $6 \%$ aluminum, and $4 \%$ vanadium, and suture holes are located on both sides of the washer. The suture holes for each washer were $1.8 \mathrm{~mm}$ in diameter. The three threading procedures used with these washers are shown in Fig. 4. To distinguish different threading methods using the same washer, threading only one hole of the ring washer was denominated "ring washer-1" and two holes "ring washer-2." When locating the reference point of the washer-suture interface, the angle of the thread was set to 15 or $45^{\circ}$ (Fig. 5).

\section{Statistical analysis}

An analysis of qualification typeIwas performed to elucidate the most impactful element for a substantial tension band suture. The Kruskal-Wallis test was used to compare different suture materials and threading methods. The Bonferroni procedure was conducted for post hoc comparisons to clarify groups when statistical significance was detected. The effect of the threading angle was tested by the Mann-Whitney $U$ test. All statistical analyses were performed using IBM SPSS Statistics24 (IBM Japan, Tokyo, Japan) software. A $P<0.05$ was considered significant.

\section{Results}

The results of each combination are shown in Table 1. Larger numeric values indicate resistance to frictional force and loading. The most durable combination in the cyclic loading test was threading the FiberWire to the washer ring using only one hole (ring washer-1) at $45^{\circ}$, which averaged 173 vertical motions before thread rupture. In contrast, the most vulnerable combination was threading Ethibond to the disc washer at $15^{\circ}$, averaging only 1.3 vertical motions. More than a hundredfold difference in durability existed between these two combinations. According to the analysis of qualification typeI,

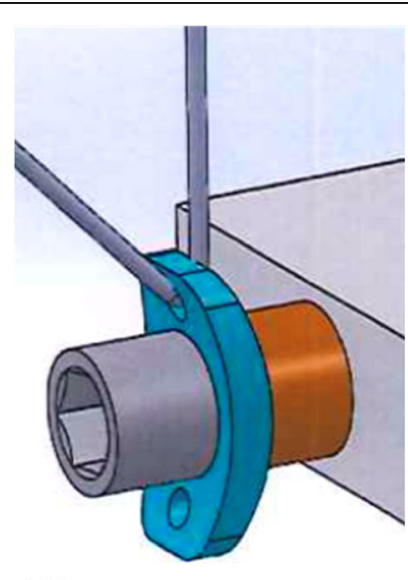

(A)

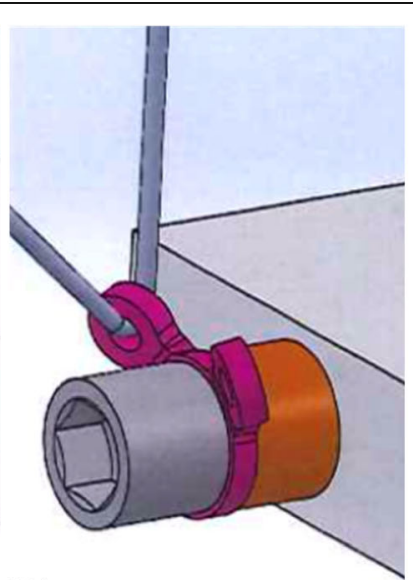

(B)

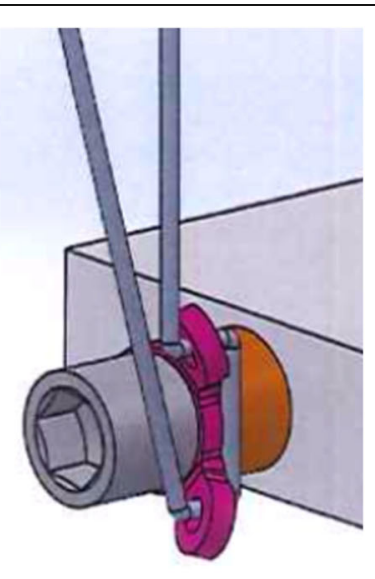

(C)

Fig. 4 Three threading methods are shown. Using (a) and ring washer. Threading a hole to ring washer was defined ring washer-1 (b) and two holes ring washer-2 (c) 


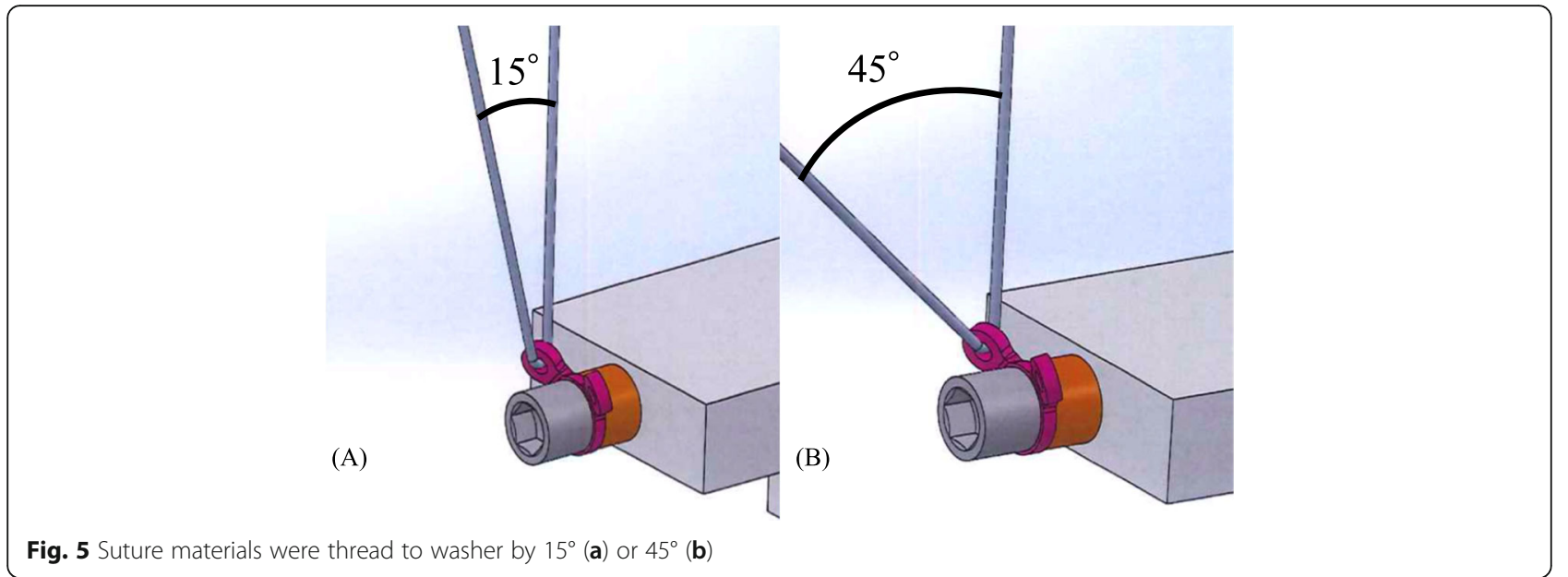

FiberWire was overwhelmingly a center of interest by $59 \%$ of the contribution ratio, followed by the ring washer- 1 at $21 \%$, the disc washer at $10 \%$, and $45^{\circ}$ at $4 \%$. Among these eight experimental elements, Ethibond and $15^{\circ}$ had the most negative effect on the results. Hence, an additional analysis of angles and washers among FiberWire group was performed.

\section{Suture materials}

The FiberWire group, mean 92.9 (SD 64.6), demonstrated prominent strength in the average number of reciprocating motions, compared to the Ethibond, mean 2.3 (SD 0.9), and Surgilon groups, mean 3.1 (SD 1.0) ( $P$ $<0.001$ ) (Table 2). Breakage of all suture materials occurred at the suture-washer interface, and no failure or loosening of the knots was observed. The rupture pattern differed according to the suture material: FiberWire gradually eroded until the loss of equilibrium; whereas the rupture of Ethibond and Surgilon occurred suddenly.

\section{Angle of suture}

In comparing the two suture angles, the $45^{\circ}$ group, mean 38.9 (SD 68.1), showed a higher average than the $15^{\circ}$ group, mean 26.3 (SD 42.2); however, it was without significance $(P=0.57)$. The superiority of the wider angle

Table 1 Number of times to failure for each combination

\begin{tabular}{|c|c|c|c|c|c|c|c|c|c|}
\hline \multirow[b]{2}{*}{$15^{\circ}$} & \multicolumn{3}{|c|}{ Ethibond } & \multicolumn{3}{|c|}{ FiberWire } & \multicolumn{3}{|c|}{ Surgilon } \\
\hline & $\# 1$ & \#2 & \#3 & $\# 1$ & $\# 2$ & \#3 & $\# 1$ & $\# 2$ & \#3 \\
\hline Disc washer & 1 & 2 & 1 & 46 & 60 & 58 & 2 & 2 & 2 \\
\hline Ring washer-1 & 2 & 2 & 2 & 137 & 126 & 122 & 3 & 3 & 3 \\
\hline Ring washer-2 & 4 & 2 & 3 & 22 & 20 & 73 & 3 & 4 & 5 \\
\hline $45^{\circ}$ & $\# 1$ & \#2 & \#3 & $\# 1$ & $\# 2$ & \#3 & $\# 1$ & \#2 & \#3 \\
\hline Disc washer & 2 & 2 & 1 & 172 & 182 & 63 & 3 & 2 & 2 \\
\hline Ring washer-1 & 2 & 2 & 2 & 219 & 157 & 143 & 3 & 2 & 3 \\
\hline Ring washer-2 & 4 & 3 & 4 & 17 & 36 & 20 & 5 & 4 & 5 \\
\hline
\end{tabular}

also applied to each suture material, but again, the difference was not significant (Table 3).

\section{Washer and threading methods}

Regarding the threading procedure, the ring washer-1 group had the highest endurance on average, mean 51.8 (SD 72.4), followed by the disc washer group, mean 33.5 (SD 55.6), and the ring washer-2 group, mean 13.0 (SD 17.2). Statistical significance was not observed among these three groups $(P=0.15)$; however, there was a significant difference in the threading methods of the FiberWire group $(P=0.006)$ (Table 4). The post hoc test revealed a significant difference in the durability of the ring washer-2, mean 31.3 (SD 21.5), and ring washer-1, mean 150.7 (SD $35.7)$, among FiberWire groups $(P<0.001)$.

\section{Discussion}

The multiple fixation techniques described in literature indicate that the optimal treatment for displaced proximal humeral fractures continues to be controversial [7, $8,11,19-21]$. The preferred operation technique depends on fracture type, patient age, bone quality, and functional expectation. Surgery, using an angular and sliding stable antegrade nail (Targon $\mathrm{PH}$ ), is a standard treatment option which can provide good functional results $[10,22,23]$. Supplemental tension band sutures are recommended for proximal humeral fracture treatment

Table 2 Average number of times to failure for each suture

\begin{tabular}{ll}
\hline Suture group & Number of reciprocating motion \\
\hline FiberWire & $92.9(64.6)$ \\
Ethibond & $2.3(0.9)$ \\
Surgilon & $3.1(1.0)$ \\
$P$ & $<.001$
\end{tabular}

Values are mean

Abbreviation: $S D$ standard deviation 
Table 3 Average number of times to failure for each suture by different angles

\begin{tabular}{lllll}
\hline Angles & FiberWire & Ethibond & Surgilon & Total \\
\hline $15^{\circ}$ & $73.8(41.9)$ & $2.1(0.9)$ & $3.0(1.0)$ & $26.3(42.2)$ \\
$45^{\circ}$ & $111.0(74.7)$ & $2.4(1.0)$ & $3.2(1.1)$ & $38.9(68.1)$ \\
$P$ & .29 & .46 & .74 & .57
\end{tabular}

Values are mean

Abbreviation: $S D$ standard deviation

in a myriad of literature with favorable clinical results [12-17]. Badman et al. advocated that effectiveness derives from the counterforce to the natural deforming forces of the rotator cuff [12]. According to Park et al., tension band sutures placed between the rotator cuff and the head of the interlocking screw or washer, using no. 5 Ethibond suture material, increase the stability of the bone fragment with good postoperative shoulder function [15]. Badman et al. and Shukla et al. reported that locked plating with tension band rotator cuff fixation using a minimum of four or five no. 2 FiberWire sutures can prevent fixation failure and result in favorable clinical outcomes [12, 17]. Micic et al. emphasized the importance of applying a tension band suture over the tuberosity for additional stability; they report that negligence of this procedure is a risk factor for revision surgery [24]. On the other hand, there is a contradictory result which reports the invalidity of the tension band suture. Arvesen et al. performed a cadaveric study and concluded that tension-relieving rotator cuff sutures with no. 5 FiberWire do not add stability to the repair of 3-part proximal humeral fractures [25]. Furthermore, Voigt et al. also reported no contribution to reduce interfragmentary motion by additive fiber-cerclages in unstable 3-part fracture model with an intact rotator cuff [26]. The necessity of the tension band suture is yet controversial and heterogeneity of surgical indication exists. Moreover, suture materials, artifacts, and threading methods for tension band suture vary in the literature, which hinders discussions of its effectiveness. In this study, we attempted to present an ideal method from a mechanical viewpoint by focusing on the combination of three essential elements of the tension band suture: the suture material, threading angle, and washer.

Table 4 Average number of times to failure by threading methods

\begin{tabular}{lll}
\hline Threading methods & FiberWire & All sutures \\
\hline Disc washer & $96.8(62.4)$ & $33.5(55.6)$ \\
Ring washer-1 & $150.7(35.7)$ & $51.8(72.4)$ \\
Ring washer-2 & $31.3(21.5)$ & $13.0(21.5)$ \\
$P$ & .006 & .15 \\
\hline
\end{tabular}

Values are mean

Abbreviation: $S D$ standard deviation
FiberWire, a representative non-absorbable suture made of multi-strand, long-chain, ultra-high molecular weight polyethylene (UHMWPE), demonstrated higher strength than the other conventional sutures as Barber et al. reported; its superiority showed remarkable statistical significance in our study $(P<0.001)$ [27]. Moreover, the rupture pattern differed between FiberWire and the other suture materials. This might be ascribed to its structural composition and loading type. FiberWire consists of a UHMWPE core with a braided jacket of polyester and UHMWPE; whereas Ethibond and Surgilon are made of polyester and nylon with a braided structure coated with polybutylate and silicone. Wright et al. verified that FiberWire's non-braided core, protected in its polyester jacket, resists elongation, and enables it to maintain strength, even when the suture is partially cut [28]. In most previous biomechanical experiments, the load to failure tensile tests is performed by mere continuous traction to the suture [18]. We performed cyclic loading in this study to replicate the type of load for which the tension band suture is considered to be exposed after surgery by the motion of the shoulder joint. Frictional force occurs repeatedly between the suture material and washer, in addition to tensile force. We think the gradual erosion of FiberWire by frictional force might be a consequence of the structural characteristics mentioned above. In spite of this distinctive property of FiberWire, Abbi et al. and Barber et al. reported that knot slippage occurred more frequently with FiberWire than Ethibond, which must be considered another mode of tension band suture failure [27, 29]. In our study, there was no knot slippage, regardless of suture materials, utilizing five square knots tied on each end.

Theoretically, when loading an identical tensile force to suture material, the normal force at the contact point between the washer and the suture material increases as the threaded suture makes an acute angle. As a result of this larger dynamic friction force, the $15^{\circ}$ group had a tendency to be vulnerable; although no statistical significance existed between angle groups. We assume that threading the suture to the washer at a wider angle is desirable for rupture prevention. However, in clinical settings, the threading angle is affected by multiple conditions, such as design of artifact, bone fragments, and soft tissue.

Artifacts used for tension band sutures also play an important role. Generally, when treating with plates, dedicated eyelets in the plate are used to thread the suture $[12,17]$. However, Cho et al. illustrated the difficulty in providing tension to sutures using eyelets in the plates because the knots might eventually loosen [13]. There are plural methods for tension band sutures using IMN. Hao et al. introduced a technique to augment tuberosity fixation by threading suture holes on the 
interlocking screws [30]. This might potentially have the same issue as threading to eyelets in the plate; additionally, the contraction of the rotator cuff can lead to screw backout. Park et al. performed tension band and locking sutures in addition to IMN and reported good clinical outcomes [16]. They hung the sutures only at the head of the interlocking screw, which we consider technically difficult with a potential risk of suture slippage or knot failure. To prevent these risks, washers were introduced. Cho et al. used two washers with plates to interpose the suture material and transmit the tension through the sutures [13]. Kim et al. employed a washer to secure the suture and compensate for the shortcomings of the tension band sutures with IMN [14]. We advocate this technique and are attempting to refine the method. When threading the suture to the washer, frictional force becomes a problem. The type of washer did not significantly affect the result when threading to a single hole; however, threading both holes of the washer ring in succession (washer ring-2) militated against the durability. Thus, engendering frictional wear at two points is a risk for early rupture.

Our study has several limitations. This is an in vitro study, so our model does not completely replicate the in vivo environment. Different external forces might act on the tension band suture when using a bone model of proximal humeral fracture. Additional cadaveric study might reveal those dynamics. Also, the sample size for each combination was limited to three, because we used a brand-new washer for each trial to ensure a uniform environment.

\section{Conclusion}

Our study demonstrated that a supplemental tension band suture using FiberWire with a single-hole ring washer threaded at a wider angle is recommended from a mechanical viewpoint.

\section{Abbreviations}

ORIF: Open reduction and internal fixation; IMN: Intramedullary nails; UHMWPE: Ultra-high molecular weight polyethylene

\section{Acknowledgements}

We gratefully acknowledge the work of Farmax Medical Inc.

\section{Authors' contributions}

TK and YM elaborated the plan and arranged for the experiment in Farmax Medical Inc. TS, SY, and MS performed the most part of the laboratory work. $\mathrm{HI}$ was a major contributor in writing the manuscript. All authors read and approved the final manuscript.

\section{Funding}

This research did not receive any specific grant from funding agencies in the public, commercial, or not-for-profit sectors.

\section{Availability of data and materials}

All data generated or analyzed during this study are included in this published article.
Ethics approval and consent to participate

Not applicable.

\section{Consent for publication}

Not applicable.

\section{Competing interests}

The authors declare that they have no competing interests.

\section{Author details}

${ }^{1}$ Department of Orthopaedic Surgery (Ohashi), School of Medicine, Toho University, 2-22-36 Ohashi, Meguro-ku, Tokyo 153-8515, Japan. ${ }^{2}$ Department of Orthopaedic Surgery (Ohashi), Toho University Graduate School of Medicine, 5-21-16 Omorinishi, Otaku, Tokyo 143-8540, Japan.

Received: 15 June 2020 Accepted: 13 August 2020

Published online: 20 August 2020

\section{References}

1. Court-Brown CM, Caesar B. Epidemiology of adult fractures: a review. Injury. 2006;37(8):691-7. https://doi.org/10.1016/j.injury.2006.04.130.

2. Tsuda T. Epidemiology of fragility fractures and fall prevention in the elderly: a systematic review of the literature. Curr Orthop Pract. 2017;28(6):580-5. https://doi.org/10.1097/BCO.0000000000000563.

3. Lee $\mathrm{SH}$, Dargent-Molina P, Bréart G. Risk factors for fractures of the proximal humerus: results from the EPIDOS prospective study. J Bone Miner Res. 2002;17(5):817-25. https://doi.org/10.1359/jbmr.2002.17.5.817.

4. Neer CS. Displaced proximal humeral fractures. I. Classification and evaluation. J Bone Joint Surg Am. 1970;52(6):1077-89. https://doi.org/10. 1097/01.blo.0000198718.91223.ca.

5. Nho SJ, Brophy RH, Barker JU, Cornell CN, MacGillivray JD. Management of proximal humeral fractures based on current literature. J Bone Joint Surg Am. 2007:89(Suppl 3):44-58. https://doi.org/10.2106/JBJS/G/00648.

6. Dilisio MF, Nowinski RJ, Hatzidakis AM, Fehringer EV. Intramedullary nailing of the proximal humerus: evolution, technique, and results. J Shoulder Elb Surg. 2016;25(5):130-8. https://doi.org/10.1016/j/jse/2015.11.106.

7. Gracitelli, M.E.., Malavolta, E.A., Assunção, J.H., Kojima, K.E., dos Reis, P.R., Silva, J.S., \& et al. (2016). Locking intramedullary nails compared with locking plates for two- and three-part proximal humeral surgical neck fractures: a randomized controlled trial. J Shoulder Elb Surg, 25(5), 695-703. doi: https:// doi.org/10.1016/j.se.2016.02.003.

8. Fakler JKM, Hogan C, Heyde CE, John T. Current concepts in the treatment of proximal humeral fractures. Orthopedics. 2008;31(1):42-51. https://doi. org/10.3928/01477447-20080101/13.

9. Boileau P, d'Ollonne T, Bessière C, Wlison A, Clavert P, Hatzidakis AM, et al. Displaced humeral surgical neck fractures: classification and results of thirdgeneration percutaneous intramedullary nailing. J Shoulder Elb Surg. 2019; 28(2):276-87. https://doi.org/10.1016/jse.2018.07.010.

10. Gradl, G. Dietze, A., Arndt, D., Beck, M., Gierer, P., Börsch, T., \& et al. (2007). Angular and sliding stable antegrade nailing (Targon $\mathrm{PH}$ ) for the treatment of proximal humeral fractures. Arch Orthop Trauma Surg, 127(10), 937-944. doi:https://doi.org/10.1007/s00402-007-0425-5.

11. Smith AM, Mardones RM, Sperling JW, Cofield RH. Early complications of operatively treated proximal humeral fractures. J Shoulder Elb Surg. 2007; 16(1):14-24. https://doi.org/10.1016/j.jse.2006.05.008.

12. Badman B, Frankle M, Keating C, Henderson L, Brooks J, Mighell M. Results of proximal humeral locked plating with supplemental suture fixation of rotator cuff. J Shoulder Elb Surg. 2011;20(4):616-24. https://doi.org/10.1016/ jse.2010.08.030

13. Cho $\mathrm{CH}$, Jung $\mathrm{GH}$, Song KS. Tension suture fixation using 2 washers for proximal humeral fractures. Orthopedics. 2012;35(3):202-5. https://doi.org/ 10.3928/01477447-20120222-05.

14. Kim KC, Rhee KJ, Shin HD. Tension band sutures using a washer for a proximal humerus fracture. J Trauma. 2008;64(4):1136-8. https://doi.org/10. 1097/TA.0b013e318076b514.

15. Park MC, Murthi AM, Roth NS, Blaine TA, Levine WN, Bigliani LU. Two-part and three-part fractures of the proximal humerus treated with suture fixation. J Orthop Trauma. 2003;17(5):319-25. https://doi.org/10.1097/ 00005131-200305000-00001.

16. Park JY, An JW, Oh JH. Open intramedullary nailing with tension band and locking sutures for proximal humeral fracture: hot air balloon technique. J 
Shoulder Elb Surg. 2006;15(5):594-601. https://doi.org/10.1016/j.jse.2006.01. 001.

17. Shukla DR, MCAnany S, Pean C, Overley S, Lovy A, Parsons BO. The results of tension band rotator cuff suture fixation of locked plating of displaced proximal humerus fractures. Injury. 2017;48(2):474-80. https://doi.org/10. 1016/j.injury.2016.12.022.

18. Burkhart SS, Johnson TC, Wirth MA, Athanasiou KA. Cyclic loading of transosseous rotator cuff repairs: tension overload as possible cause of failure. Arthroscopy. 1997;13(2):172-6. https://doi.org/10.1016/s07498063(97)90151-1.

19. Gradl G, Dietze A, Kääb M, Hopfenmüller W, Mittlmeier T. Is locking nailing of humeral head fractures superior to locking plate fixation? Clin Orthop Relat Res. 2009;467(11):2986-93. https://doi.org/10.1007/s11999-009-0916-5.

20. Helfen, T., Siebenburger, G., Mayer, M., Böcker, W., Ockert, B., \& Haasters, F. (2016). Operative treatment of 2-part surgical neck fractures of the proximal humerus (AO 11-A3) in the elderly: Cement augmented locking plate Philos $^{\text {TM }}$ vs. proximal humerus nail MultiLoc ${ }^{\oplus}$. BMC Musculoskelet Disord, 17(1), 448. doi:https://doi.org/10.1186/s12891-016-1302-6.

21. Rangan A, Handoll H, Brealey S, Jefferson L, Keding A, Martin BC, et al. Surgical vs nonsurgical treatment of adults with displaced fractures of the proximal humerus: the PROFHER randomized clinical trial. JAMA. 2015; 313(10):1037-47. https://doi.org/10.1001/jama.2015.1629.

22. Mathews J, Lobenhoffer P. The Targon ${ }^{\oplus} \mathrm{PH}$ for unstable fractures of the proximal humerus. Oper Orthop Traumatol. 2007;19(3):255-75. https://doi. org/10.1007/s00064-007-1205-7.

23. Mittlmeier TW, Stedtfeld HW, Ewert A, Beck M, Frosch B, Gradl G. Stabilization of proximal humeral fractures with an angular and sliding stable antegrade locking nail (Targon PH). J Bone Joint Surg Am. 2003;85A(Suppl 4):136-46. https://doi.org/10.2106/00004623-200300004-00019.

24. Micic ID, Kim KC, Shin DJ, Shin SJ, Kim PT, Park IH, et al. Analysis of early failure of the locking compression plate in osteoporotic proximal humerus fractures. J Orthop Sci. 2009;14(5):596-601. https://doi.org/10.1007/s00776009-1382-3.

25. Arvesen JE, Gill SW, Sinatra PM, Eng M, Bledsoe G, Kaar SG. Biomechanical contribution of tension-reducing rotator cuff sutures in 3-part proximal humerus fractures. J Orthop Trauma. 2016;30(8):262-6. https://doi.org/10. 1097/BOT.00000000000000575.

26. Voigt C, Hurschler C, Rechi L, Vosshenrich R, Lill H. Additive fiber-cerclages in proximal humeral fractures stabilized by locking plates. Acta Orthop. 2009;80(4):465-71. https://doi.org/10.3109/17453670903110659.

27. Barber FA, Herbert MA, Beavis RC. Cyclic load and failure behavior of arthroscopic knots and high strength sutures. J Arthroscopy. 2009;25(2):1929. https://doi.org/10.1016/j.arthro.2008.09.010.

28. Wright PB, Budoff JE, Yeh ML, Kelm ZS, Luo ZP. Strength of damaged suture: an in vitro study. Arthroscopy. 2006;22(12):1270-5. https://doi.org/10. 1016/.j.arthro.2006.08.019.

29. Abbi G, Espinoza L, Odell T, Mahar A, Pedowitz R. Evaluation of 5 knots and 2 suture materials for arthroscopic rotator cuff repair: very strong sutures can still slip. Arthroscopy. 2006;22(1):38-43. https://doi.org/10.1016/j.arthro. 2005.10.010.

30. Hao TD, Huat AWT. Surgical technique and early outcomes of intramedullary nailing of displaced proximal humeral fractures in an Asian population using a contemporary straight nail design. J Orthop Surg (Hong Kong). 2017;25(2):1-9. https://doi.org/10.1177/2309499017713934.

\section{Publisher's Note}

Springer Nature remains neutral with regard to jurisdictional claims in published maps and institutional affiliations.

Ready to submit your research? Choose BMC and benefit from:
- fast, convenient online submission
- thorough peer review by experienced researchers in your field
- rapid publication on acceptance
- support for research data, including large and complex data types
- gold Open Access which fosters wider collaboration and increased citations
- maximum visibility for your research: over 100M website views per year
At BMC, research is always in progress.
Learn more biomedcentral.com/submissions

